Pramanik, A. and Basak, A. and Islam, M.N. 2015. Effect of reinforced particle size on wire EDM of MMCs. International Journal of Machining and Machinability of Materials. 17 (2): pp. 139-149. 


\title{
Effect of the reinforced particles size on wire EDM of MMCs
}

\begin{abstract}
This paper investigates the size effect of the reinforced particles on wire electrical discharge machining (EDM) of metal matrix composites (MMCs) in terms of material removal rate (MRR), surface integrity and wear of wire electrode (WE). It was found that the bigger particles significantly reduce the MRR as those have higher ability to protect the matrix material from EDM spark compare to that of smaller particles. The machined surfaces are full of solidified melted matrix, splash of melted material, cavities and blisters which are not significantly affected by the particle size. Spattering and splashing may have contributed to transfer of materials between WE and MMCs. The diameter of the WE was reduced nonlinearly with the increase of reinforced particles size after machining. The least reduction of the electrode diameter was noted for the unreinforced matrix material.
\end{abstract}

Keyword: Wire EDM, MMCs, size of reinforcement, machinability

\section{Introduction}

Though MMCs are difficult to machine by conventional machining processes [1], the research on the particle reinforced MMCs indicates that these materials can be machined by EDM. However, the low electrical conductivity and the high thermal resistance of the reinforcements slow the MRR [2]. Generally, higher power input with the combination of process parameters increase the MRR and surface roughness [3] [4] [5]. Hung et al. [6] noted that the current alone dominates the surface finish. Manna and Bhattacharyya [7] noted that the open-gap voltage is the most influential parameters for the MRR and cutting speed. Wire tension and wire feed rate mostly affect the surface roughness. Gatto and Iuliano [8] noted similar machining speeds for SiC/2009 Al alloy with 15\% whiskers and with 20\% particles reinforcement composites though the surface roughness of $15 \%$ whiskers composite is less than that of $20 \%$ particles composite. Rozenek et al. [3] noted that the reinforcement material affects the machining speed. The maximum cutting speed of $\mathrm{SiC}$ and $\mathrm{Al}_{2} \mathrm{O}_{3}$ reinforced 
composites are approximately 3 and 6.5 times smaller than that of aluminium alloy (AlSi7Mg). Guo et al. [5] experienced frequent wire breakage when low energy is employed by low pulse duration and voltage due to high blind feeding in $20 \% \mathrm{Al}_{2} \mathrm{O}_{3}$ particle reinforcement Al6061 composite. Yan et al. [9] found that the increase of $\mathrm{Al}_{2} \mathrm{O}_{3}$ particle vol.\% in 6061Al from 10 to 20 did not change machining speed but caused more frequent wire breakage, narrower slit, rougher machined surface finish, wire shift, and wider and deeper craters on the wire surface. These can be reduced by low wire tension, high flushing rate and high wire speed. Saha et al. [10] experienced unstable EDM due to the presence of TiC particles and formation of $\mathrm{Fe}_{2} \mathrm{O}_{3}$ while machining 5 vol.\% TiC reinforced $\mathrm{Fe}$ in situ MMC. Liu et al. [4] found that the high current or high concentrations of electrolyte stimulated the electrochemical and increased the MRR for $\mathrm{Al}_{2} \mathrm{O}_{3}$ particle reinforced 6061 aluminium alloy. The presence of silicon in the matrix material within the re-cast layer indicates that silicon diffuses from the SiC-particles into the matrix alloy [11]. The thickness of the re-cast layer increases with increased discharge current and longer pulse on-times [2].

The above discussion indicates that the effect of the reinforcement size on the EDM of MMCs has not been investigated yet though the reinforcement size affects the properties of the MMCs significantly. There is a trend for MMCs to have smaller size of reinforced particles to widen its application $[12,13]$. In addition, the mechanism of EDM has not been understood clearly. Thus the investigation on the size effect of reinforcement particles on wire EDM of MMCs is imperatively needed. This issue has been addressed in this study to provide in-depth understanding on the responses of the MMCs with different particle sizes on the EDM process and the machining mechanism.

\section{Experiment}

The wire EDM of MMCS was performed in a FANUC ROBOCUT $\alpha-0 \mathrm{iD}$ machine. A slot of $7 \mathrm{~mm}$ long was machined on a plate of $137 \times 42 \times 9 \mathrm{~mm}^{3}$ in each experiment. The MMCs of 6061 aluminium alloy matrix material reinforced with 10 vol\% SiC particles of 13, 3, $0.7 \mu \mathrm{m}$ size (approximately) were machined. The unreinforced 6061 aluminum alloy was also machined under identical condition. All materials were hot extruded and treated in T1 condition. The machining parameters were: wire speed $10 \mathrm{~m} / \mathrm{min}$, wire tension $1200 \mathrm{gf}$, flushing rate $10 \mathrm{l} / \mathrm{min}$, open circuit voltage $85 \mathrm{~V}$, servo voltage $44 \mathrm{~V}$, pulse on time $4 \mu \mathrm{s}$, and Zn coated brass wire of diameter $0.25 \mathrm{~mm}$. The machining conditions were selected based on the available literature and the available facilities laboratory. 


\section{Results}

\subsection{Machined surfaces}

The SEM micrograph (Quanta 450 FEG SEM) and corresponding EDAX spectra of the machined surfaces in Fig. 1 shows that all surfaces consist of solidified melted materials, crater due to spark and blisters due to splash of the molten metals. There are also reinforced particles on the machined surfaces of MMCs as evidence by EDAX spectra. The presence of $\mathrm{Si}$ in the machined surface indicates that it diffuses from $\mathrm{SiC}$ particles at high temperature. On the other hand, the presence of $\mathrm{Zn}$ and $\mathrm{Cu}$ indicates the transfer of WE material to workpiece by spattering. The $\mathrm{wt} \%$ of the transferred elements depends on the SiC particle size in MMCs, such as the highest amount of Si is noted when the particle size is biggest. Presence of $\mathrm{Cu}$ also noted in this case. With the reduction of the particle size the wt\% of Si decreases and presence of $\mathrm{Cu}$ disappears but the amount of $\mathrm{Zn}$ increases.

The surface profiles are made of many cavities where the cavities for the MMC with biggest particle size (Fig. 2(a)) are smaller compare to that of other materials. Very similar surface profiles are noted for the MMCs with 3 and $0.7 \mu \mathrm{m}$ particle size, and unreinforced matrix material (indicated by $0 \mu \mathrm{m}$ size in the graph) qualitatively and quantitatively (Fig. 2(b-c)). Fig. 3 shows that the variation of surface finish is minor among the materials considered here though the biggest reinforcement size gives the smaller surface parameters. Then those increased with the decrease of the particle size to $3 \mu \mathrm{m}$. However, with the further decrease of particle size or the absence of the reinforcement did not affect the surface finish at all. It seems that the lower speed at higher particle size produces better surface finish but the particles don't affect the surface finish when the particle size reduced to certain size.

The material removal in MMC's occur through melting and vaporising of matrix material around the ceramic particle [2]. Microscopic craters are generated on the surface machined by EDM due to random spark discharge. The size of the craters produced on the workpiece surface depends mainly upon the energy of the discharge. Thus, the surface roughness largely depends on the size of spark crater. 

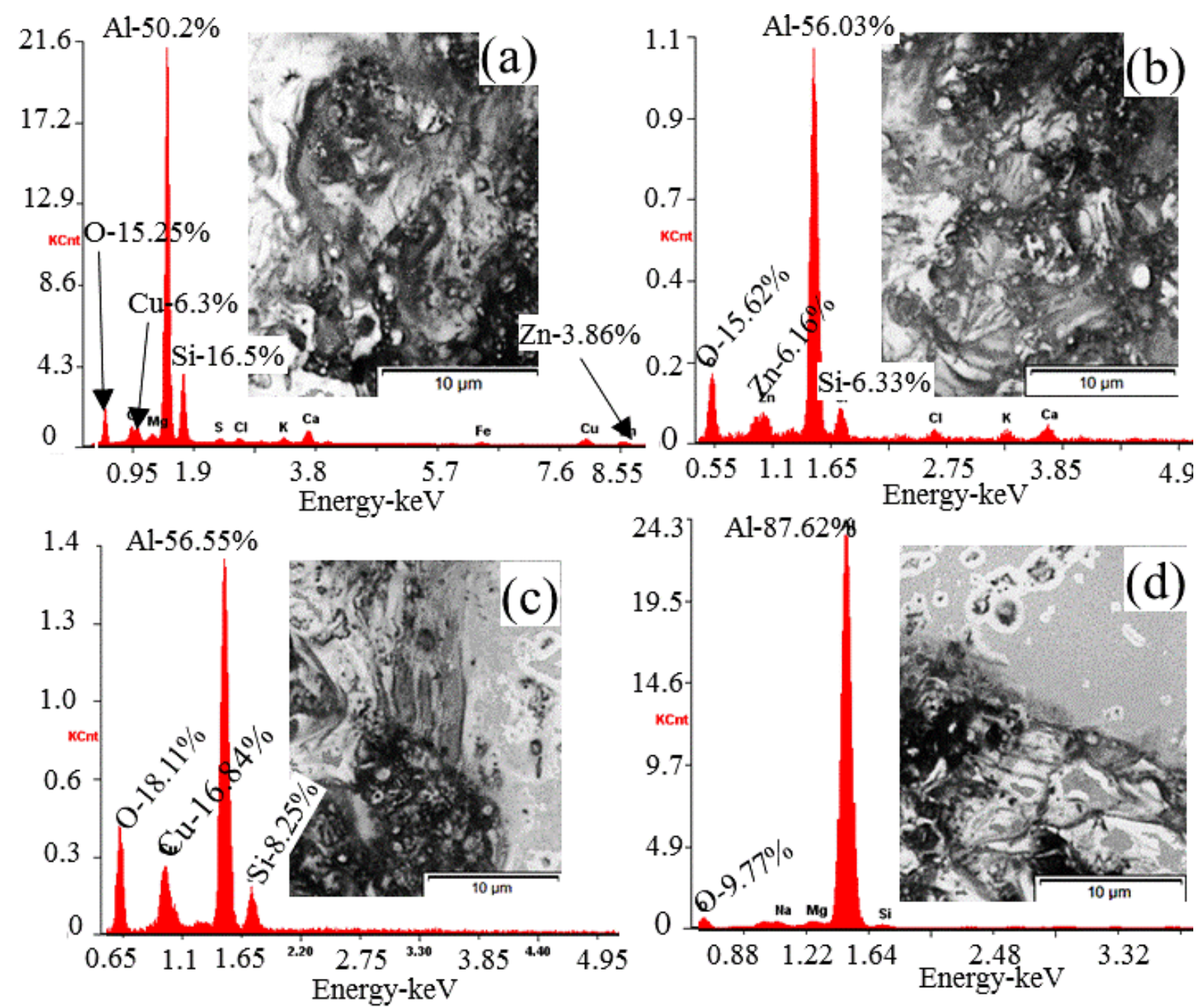

Fig. 1 Surfaces after EDM for particle size (a) 13, (b) 3, (c) $0.7 \mu$ m and (d) matrix material.

\subsection{Material removal rate (MRR)}

Fig. 3 shows that the MRR decreases with the increase of the particles size. The highest MRR occurs when particles are absent which is indicated by $0 \mu \mathrm{m}$ size in the graph. It is very natural that the bigger particles have the ability to protect the matrix material from melting and slow down the MRR. The sudden decrease of MRR from matrix material to MMC with the smallest particle size indicates that the presence of particles makes huge difference in machining process. However, the MRR decreases linearly with increase of the particle size when the size of the particles increases further. The capability of protection reduces in higher proportion when the particle size reduces further in the similar proportion below the certain size of the particles. Thus, it is unlikely that the MMR will be equivalent to that of matrix material when the the particles are in realistic size. It seems that the particles needs to be 
extremely small compare to the diameter of the WE when the MMCs and matrix materials undergoes similar kind of machining mechanism.

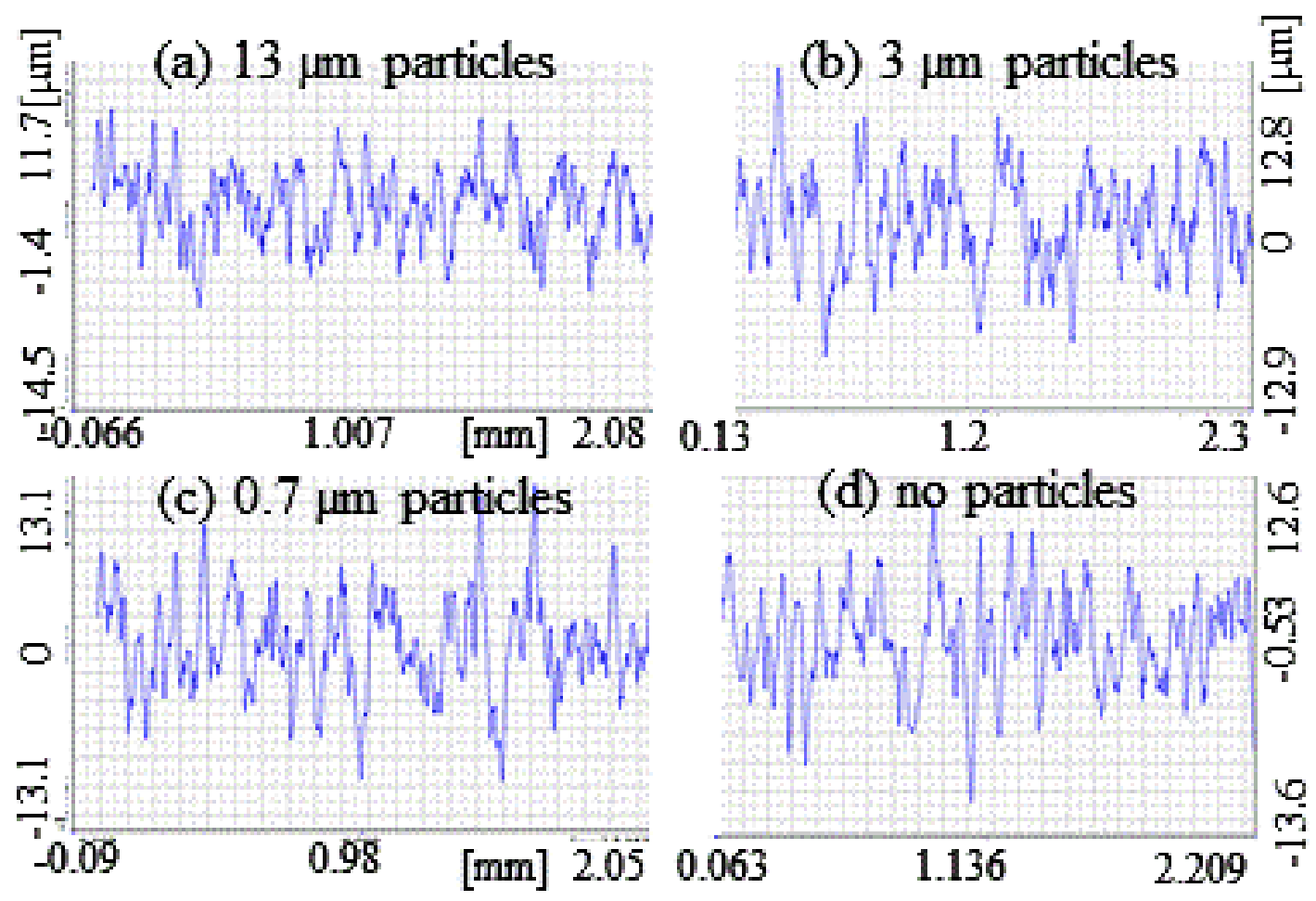

Fig. 2 Profiles of machined surfaces

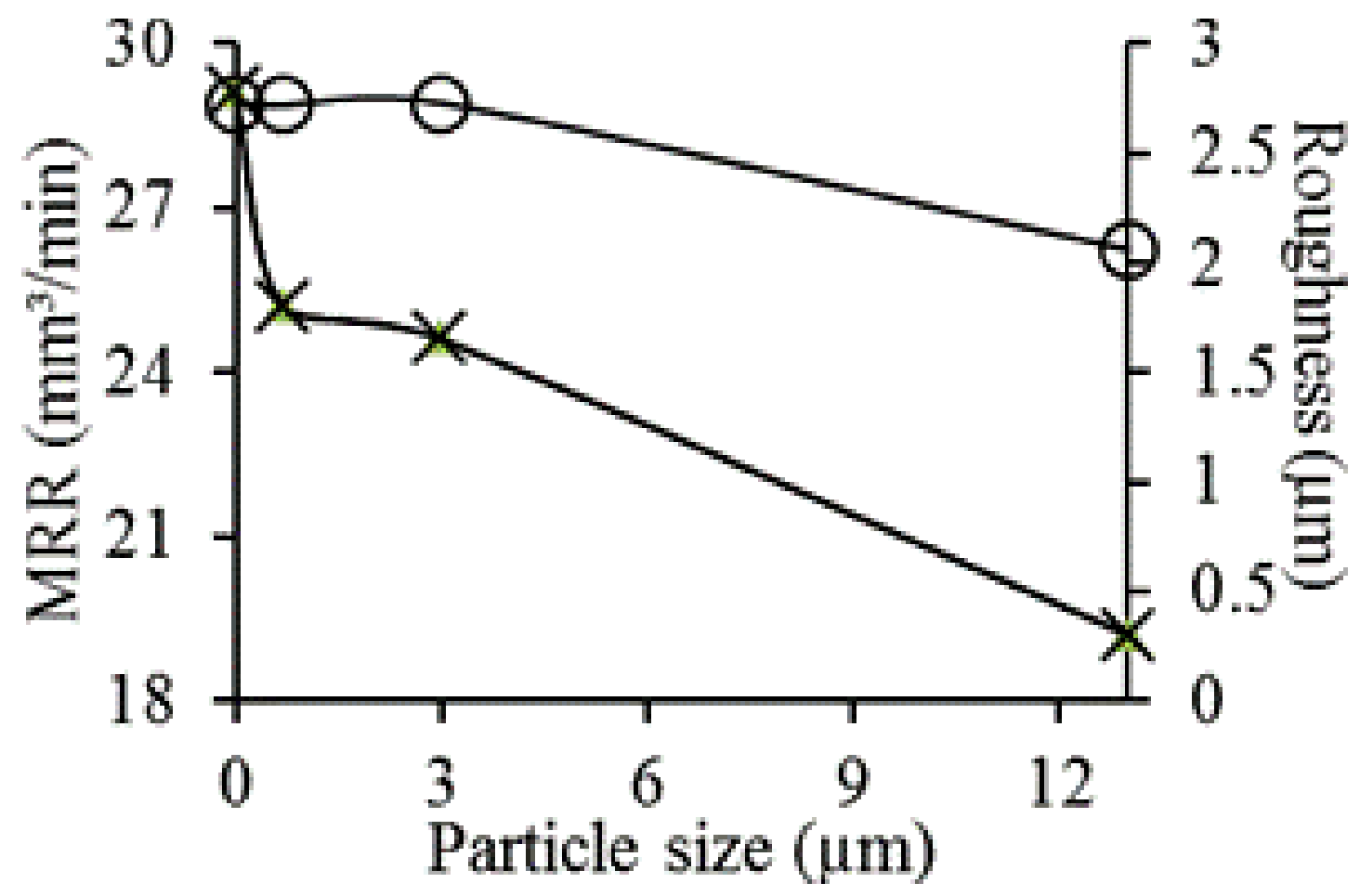

Fig. $3 \mathrm{MRR}$ and surface roughness ( $\mathrm{Ra})$ 


\subsection{Wire electrode}

The Fig. 4 shows that the diameter of the wire reduces after EDM where the maximum reduction was for MMC with biggest reinforcement and the least reduction was for the matrix material (indicated by $0 \mu \mathrm{m}$ particle size in the graph). However, the reduction of WE dimeter is not linear from the matrix material to MMC with $13 \mu$ m particles. Sudden decrease is noted from EDM of matrix material to MMC with $0.7 \mu \mathrm{m}$ particles but after that a linear decrease of diameter is noted with the further increase of particle size. This trend is very similar to the variation MMR with particle size. The surface and composition of a virgin WE are shown in Fig. 5 which shows fresh grains of $\mathrm{Zn}$ with reasonable porosity. WE was partly covered with some additional materials after machining as shown in Fig. 6. Figs 6(a) and (b) show non-covered and covered areas of the WE after EDM. The EDAX reults in Fig 6(c) shows that the WE covering materials are $\mathrm{Al}$ and $\mathrm{Si}$ which come from the workpiece material due spattering and splashing. The attachment of the workpice material is not continuous because of frequent sparking during EDM. In one spark the materials cover the WE and these are removed in the subsequent sparks. Final status WE depends on the sparking condition at the exit of the machining process. Thus the variation of diameter of WE is very common at the exit. In addition to variation of the diameter and attachement of covering materials, the electrode also undergoes sever plastic deformation which is clearly visible form the Figs. 5 and 6(a). The Fig. 6(a) shows the reduction of prosity, distortions, unevenness and burning apprearence in WE surface. The distorsion, plastic deformation and uneveness may contribute to the non-circular cross section of WE which may also contribute to the variation of the diameter.

The dielectric-fluid are affected by the stress between the negative electrode polarity and the positive work-piece polarity when a voltage is applied to the electrode and work-piece. This does not change the dielectric fluid until the electrode-to-workpiece voltage becomes equal to the dielectric-strength of the fluid. When these are equal, ionization occurs and electricity flows through the ionized column of dielectric fluid between the electrode and work-piece. The flow of electricity heats up the fluid and converts into a gas which is known as plasma which has equal number of free electrons and positive ions. The electrons readily pass through the plasma in the form of a spark. At this stage, the negative electrons are enticed to the positively charged work-picce and the positive ions are appealed to the negatively charged electrode. Generally, ionization occurs for each spark and deionization occurs after 
the electricity is turned off [14]. Thus the transfer of the work-piece material on the WE is likely.

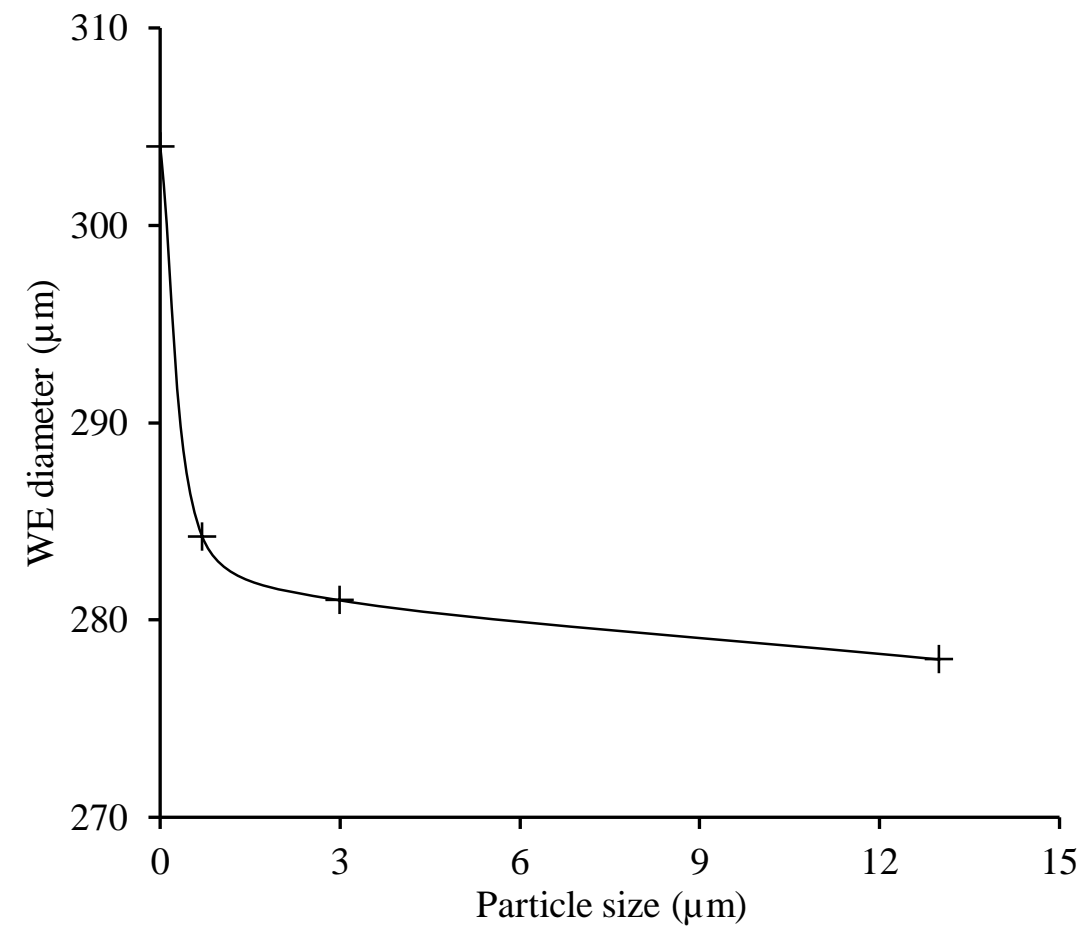

Fig. 4 WE diameter after EDM

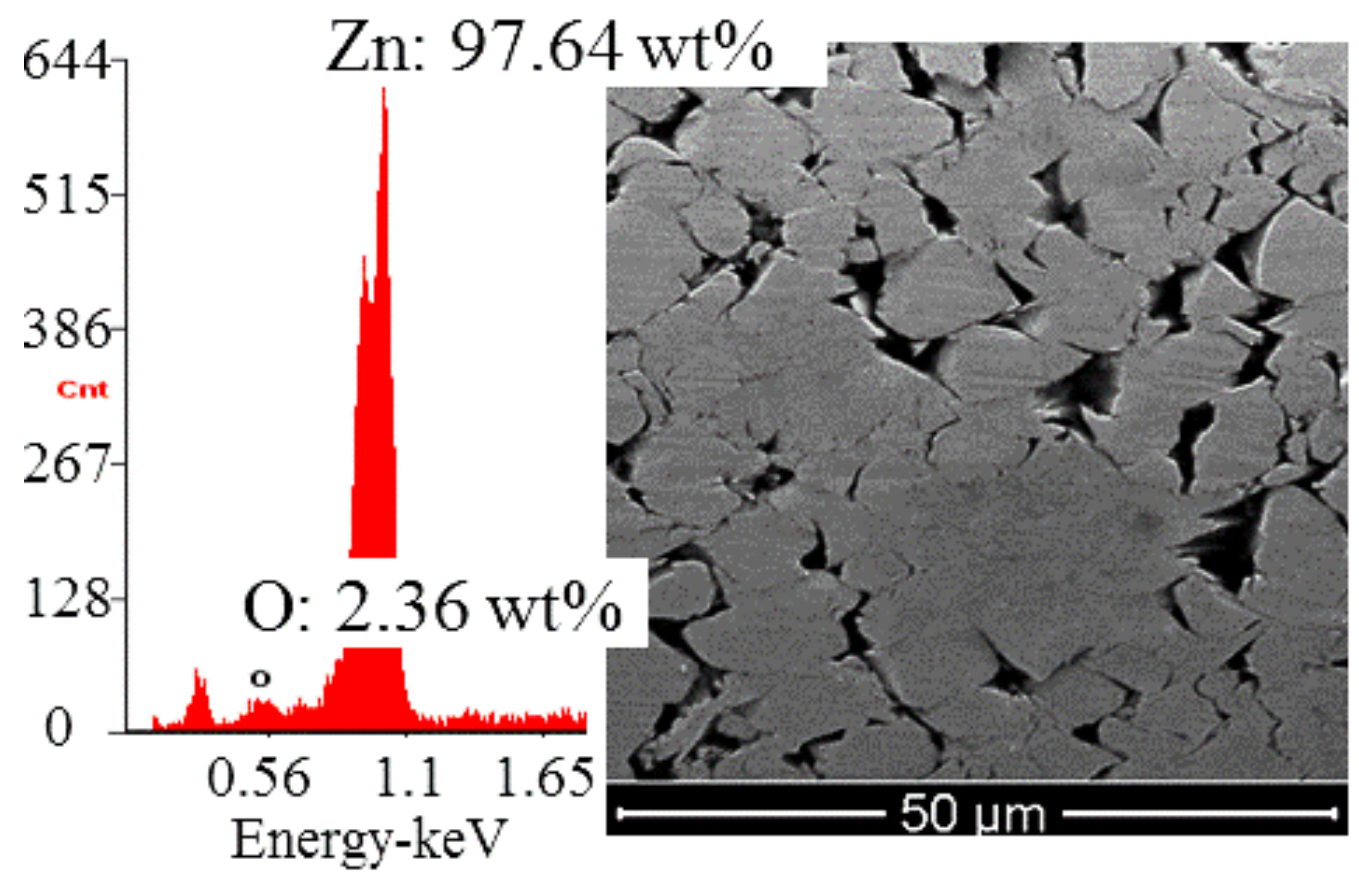

Fig. 5 The surface and EDAX of WE before EDM 

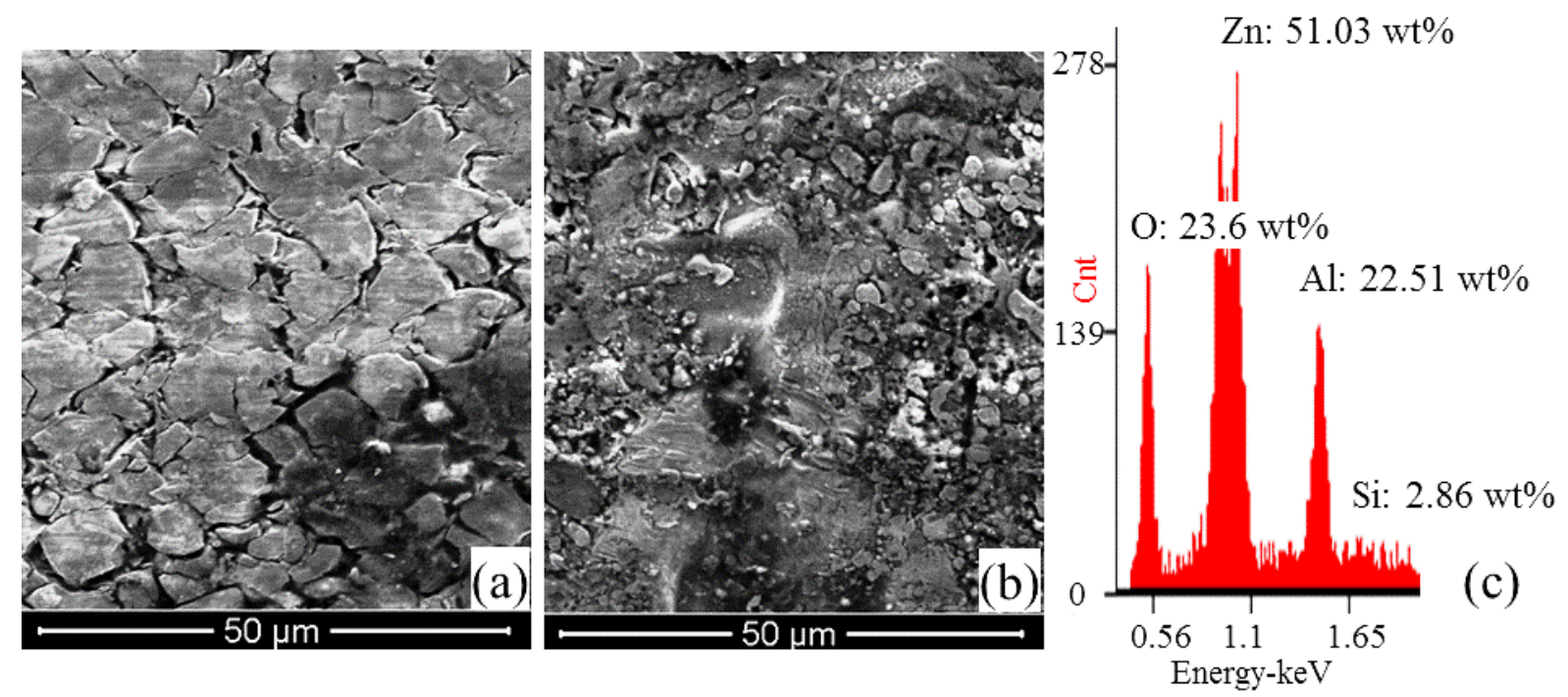

Fig. 6 WE surface after EDM (a) without and (b) with additional material, and (c) EDAX of

(b)

\section{Discussion}

MRR is generally higher at the beginning of machining but slows down due to the presence of ceramic particle and possible entrapment of particles into the spark gap [15]. According to Pramanik et al., [16] the wire encounters the ceramic particles and the EDM process becomes different to that of monolithic metals and there are three types of situations based on the location and size of the WE compare to those of the reinforced particles. The maximum spark gap/clearance was noted in the unreinforced matrix material and the minimum clearance of $67 \mu \mathrm{m}$ was noted in the MMCs reinforced with $13 \mu \mathrm{m}$ particles. As the particles are much smaller compare to the spark gap/clearance, the scenarios "the particle partly in solid material and partly in melted material" and "the particle completely inside the slit width" dominate the EDM process in this investigation. This means that the non-conductive and high melting point reinforced particles can be protruded partially into the matrix material and the other part can be over hanged in the spark gap. Thus, the particles protect the matrix material from melting and reduce the speed of material removal. At the start of the EDM, MMC and WE are kept at a distance where no electric spark takes place. The electric spark starts to take place when the WE moves close enough to the workpiece. At this stage, the matrix materials start to melt and vaporize. For bigger reinforced particles, the matrix material around the particles on the machined surface starts to disappear. However, the matrix material on the other side of the particles is shaded by particles from heat and takes time to melt which slows the MRR. At this stage the WE keeps moving slowly toward the work-piece and results in 
reduced electrode gap and higher temperature. A slower MRR during EDM process means that the workpiece material gets more time at higher temperature to melt and provides a more consistent smoother surface with uniform material removal. This also contributes to higher wear and changes of the WE. When the reinforced particles are smaller, most of the matrix melts and vaporize around the particles, and the particles may be attached to the workpiece material by a tiny link of matrix material. These links may be washed away with the flash of the electrolyte. The particles provide smaller resistance against the melting of MMC at this situation. With the much further decrease of particle size, the resistance of melting becomes comparable to that of matrix material. The dominance of microscopic craters associated with the random spark discharge causes rougher surface when machining the matrix material and MMCs reinforced with smaller particle.

The melted material flows downward due to gravity. In addition, the WE moves in two directions, i.e. the feed direction which is toward the workpice and the speed direction which is downward. The melting of the material occurs due to electric spark in point-to-point where many points take part at the same time. Thus splash and flow of metals are noted on the WE and machined surfaces. The spattering of the workpiece and WE materials takes place in the inter-electrode gap which partially coats the WE as well the machined surface. Part of the melted material is removed and the remaining molten material resolidifies by quenching at an extremely high rate due to the flushing by the dielectric, and hence a layer of re-cast material is formed which covers the machined surfaces [17]. Thus the machined surfaces appearance and roughness parameters are not affected significantly due to different sizes of reinforcements. At the start of EDM process a fresh electrode wire takes part in the machining from the top side and then comes out from the bottom side of the slit/kerf. The wire enters the slit/kerf has bigger diameter and it diameter continuously decreases with the progress of machining due to electric discharge. Thus, it is clear that along the height of the slit/kerf the wire diameter is different which produces bigger width at the top and smaller width at the bottom. In addition, the higher wear of the WE caused bigger taper for the MMC with $13 \mu \mathrm{m}$ SiC reinforced particles and the smaller reduction of wire diameter in case of matrix material produce slot with minimum taper.

\section{Conclusion}

This study reveals that the MRR decreases with the increase of the reinforcement size. The bigger reinforcement has better ability to protect the matrix material from melting. The 
surfaces generated from EDM are not affected by the size of the reinforcements unless the particles are too big. The machined surface is full of solidified melted matrix, splash of melted material, cavities and blisters. The matrix material experiences these damages very easily because of low melting point. The bigger the reinforcement size the higher the electrode wire. The wire surface also contains splash of melted material, cavities and blisters. The tapered slots were produced due to the wear of WE during EDM of all the materials. The taper was reduced with the decrease of the reinforced particles.

\section{Reference}

1. Pramanik, A., L.C. Zhang, and J.A. Arsecularatne, Deformation mechanisms of MMCs under indentation. Composites Science and Technology, 2008. 68(6): p. 13041312.

2. Muller, F., J. Monaghan, and I. Verein Deut, Electro discharge machining of a particle reinforced metal matrix composite, in 12th International Symposium for Electromachining. 1998. p. 513-522.

3. Rozenek, M., et al., Electrical discharge machining characteristics of metal matrix composites. Journal of Materials Processing Technology, 2001. 109(3): p. 367-370.

4. Liu, J.W., T.M. Yue, and Z.N. Guo, Wire Electrochemical Discharge Machining of Al2O3 Particle Reinforced Aluminum Alloy 6061. Materials and Manufacturing Processes, 2009. 24(4): p. 446-453.

5. Guo, Z.N., et al., Experimental investigation into shaping particle-reinforced material by WEDM-HS. Journal of Materials Processing Technology, 2002. 129(1-3): p. 56-59.

6. Hung, N.P., L.J. Yang, and K.W. Leong, Electrical discharge machining of cast metal matrix composites. Journal of Materials Processing Technology, 1994. 44(3-4): p. 229-236.

7. Manna, A. and B. Bhattacharyya, Taguchi and Gauss elimination method: A dual response approach for parametric optimization of CNC wire cut EDM of PRAISiCMMC. International Journal of Advanced Manufacturing Technology, 2006. 28(1-2): p. 67-75.

8. Gatto, A. and L. Iuliano, Cutting mechanisms and surface features of WED machined metal matrix composites. Journal of Materials Processing Technology, 1997. 65(1-3): p. 209-214. 
9. Yan, B.H., et al., Examination of wire electrical discharge machining of Al(2)O(3)p/6061Al composites. International Journal of Machine Tools \& Manufacture, 2005. 45(3): p. 251-259.

10. Saha, P., Tarafdar, D., Pal, S. K., Saha, P., Srivastava, A. K., \& Das, K. , Modeling of wire electro-discharge machining of TiC/Fe in situ metal matrix composite using normalized RBFN with enhanced k-means clustering technique. The International Journal of Advanced Manufacturing Technology, 2009. 43(1-2): p. 107-116.

11. Muller, F. and J. Monaghan, Non-conventional machining of particle reinforced metal matrix composite. International Journal of Machine Tools \& Manufacture, 2000. 40(9): p. 1351-1366.

12. Basak, A., A. Pramanik, and M. Islam, Failure Mechanisms of Nanoparticle Reinforced Metal Matrix Composite. Advanced Materials Research, 2013. 774: p. 548-551.

13. Pramanik, A. and G. Littlefair, Fabrication of nano-particle reinforced metal matrix composites. Advanced Materials Research, 2013. 651: p. 289-294.

14. Jameson, E.C., Electrical discharge machining. 2001: SME.

15. Hocheng, H., W.T. Lei, and H.S. Hsu, Preliminary study of material removal in electrical-discharge machining of SiC/Al. Journal of Materials Processing Technology, 1997. 63(1-3): p. 813-818.

16. Pramanik, A., Developments in the non-traditional machining of particle reinforced metal matrix composites. International Journal of Machine Tools and Manufacture, 2014: p. DOI: 10.1016/j.ijmachtools.2014.07.003.

17. Ho, K.H. and S.T. Newman, State of the art electrical discharge machining (EDM). International Journal of Machine Tools \& Manufacture, 2003. 43(13): p. 1287-1300. 